\title{
Measurement of Urinary Triclocarban and 2,4-Dichlorophenol Concentration and Their Relationship with Obesity and Predictors of Cardiovascular Diseases among Children and Adolescents in Kerman, Iran
}

\author{
Habibeh Nasab $\mathbb{D}^{1,2}$ Moghaddameh Mirzaee $\mathbb{D}^{1},{ }^{3}$ Majid Hashemi $\mathbb{D}^{1,2}$ and Saeed Rajabi $\mathbb{D}^{4}$ \\ ${ }^{1}$ Environmental Health Engineering Research Center, Kerman University of Medical Sciences, Kerman, Iran \\ ${ }^{2}$ Department of Environmental Health Engineering, Faculty of Public Health, Kerman University of Medical Sciences, \\ Kerman, Iran \\ ${ }^{3}$ Modeling in Health Research Center, Institute for Futures Studies in Health, Kerman University of Medical Sciences, \\ Kerman, Iran \\ ${ }^{4}$ Department of Environmental Health Engineering, School of Health, Shiraz University of Medical Sciences, Shiraz, Iran
}

Correspondence should be addressed to Majid Hashemi; mhashemi120@gmail.com

Received 29 April 2021; Accepted 5 January 2022; Published 20 January 2022

Academic Editor: Chunrong Jia

Copyright (C) 2022 Habibeh Nasab et al. This is an open access article distributed under the Creative Commons Attribution License, which permits unrestricted use, distribution, and reproduction in any medium, provided the original work is properly cited.

\begin{abstract}
Exposure to Endocrine-Disrupting Chemicals (EDCs) at an early age can lead to chronic diseases. 2,4-Dichlorophenol (2,4-DCP) and Triclocarban (TCC) are among EDCs that disrupt the endocrine system and alter the body's metabolism. In the present study, the hypothesis that exposure to 2,4-DCP and TCC affects obesity and predictors of cardiovascular diseases was investigated. Fasting Blood Sugar (FBS), Total Cholesterol (TC), Triglyceride (TG), Low-Density Lipoprotein (LDL), High-Density Lipoprotein (HDL (tests were performed on 79 children and adolescents. Also, blood pressure, Body Mass Index (BMI), and BMI z-score were measured to examine the hypothesis. Urinary concentrations of TCC and 2,4-DCP were measured by Gas Chromatography-Mass Spectrometry (GC/MS). Mean concentrations of TCC and 2,4-DCP $(\mu \mathrm{g} / \mathrm{L})$ were higher in obese individuals $(5.50 \pm 2.35$, $0.29 \pm 0.13$, respectively). After adjusting for possible confounding factors, the results showed an increase in TCC concentration among girls and a decrease in 2,4-DCP among boys with increasing age. The 2,4-DCP concentration among girls increased by 0.007 and 0.01 units with a one-unit increase in Diastolic Blood Pressure (DBP) and FBS, respectively. There was a significant relationship between TCC and TG (Odds Ratio $(\mathrm{OR})=1.02, p$-value $=0.007)$, LDL $(\mathrm{OR}=1.05, p$-value $=0.003)$, and $\mathrm{HDL}$ $(\mathrm{OR}=0.88, p$-value $=0.002)$. There was also a significant relationship between $2,4-\mathrm{DCP}$ and $\mathrm{TG}(\mathrm{OR}=1.02, p$-value $=0.002), \mathrm{LDL}$ $(\mathrm{OR}=1.12, p$-value $=0.007)$, and HDL $(\mathrm{OR}=0.92, p$-value $=0.02)$. Exposure to TCC and 2,4-DCP can increase some heart risk factors and increase the risk of cardiovascular diseases and obesity. However, to confirm the results of the present study, it is necessary to conduct further studies, such as cohort and case-control studies, with a larger sample size to examine the causal relationships.
\end{abstract}

\section{Introduction}

One of the serious problems in recent years has been the prevalence of obesity among children and adolescents [1-3]. Obesity leads to many diseases including diabetes, hypertension, and cardiovascular diseases $[4,5]$. People who are overweight and obese during childhood are more likely to develop obesity, cardiovascular diseases such as hypertension, hyperlipidemia, and atherosclerosis during adulthood [6]. However, the spread of cardiovascular disease does not begin in childhood and adolescence, but the risk factors for cardiovascular disease often start in childhood and adolescence $[7,8]$.

These factors include disorders of blood lipid profile, which include Total Cholesterol (TC), Triglyceride (TG), Low-Density Lipoprotein (LDL), High-Density Lipoprotein 
(HDL, which is one of the most common disorders in cardiovascular disease, especially in obese people. It is well known that there is a potential link between dyslipidemia and obesity, and symptoms of dyslipidemia include decreased HDL and increased TG. Also LDL can affect blood pressure by increasing aldosterone $[9,10]$. The prevalence of hypertension in children and adolescents in developing countries has been reported to be between one and five percent through systematic review [11]. Given the rapid increase in obesity in the young population, early detection of risk factors and their prompt treatment are important to prevent or delay the onset of late-stage heart disease complications [9]. The causes of obesity have been widely studied but are not yet well understood $[8,12]$.

The main causes of obesity are genetic factors, inactivity, diet, and environmental pollutants [13-15]. Environmental pollutants include the role of endocrine-disrupting chemicals (EDCs) (such as phthalates, parabens, triclosan, triclocarban, and diphenols) in the development of chronic diseases. EDCs contain many chemicals used in industry, commerce, agriculture, and pharmacy that have entered the water, air, food, human life, and wildlife [16-18]. They can disrupt the function of the endocrine system and thus be harmful to human health $[1,2,12,19]$. Some of the factors affecting cardiovascular diseases include age, sex, diet, physical activity, and exposure to EDCs [20, 21]. Exposure to EDCs at an early age can lead to chronic diseases that, if accompanied by improper lifestyle such as inactivity, unhealthy nutrition, increases the risk of chronic diseases $[13,22]$.

EDCs cause dysfunction of thyroid and sex hormones [16] and dysfunction of the nervous system [23]. They also increase the risk of cardiovascular diseases and obesity [16]. EDCs also play a key role in causing cardiovascular problems [23]. The onset and progression of some of the factors affecting cardiovascular diseases can begin in the critical period of childhood and adolescence [7]. Some EDCs have a long half-life, which is why they have a stable higher level in the environment [24].

2,4-Dichlorophenol (2,4-DCP) is a lipophilic chlorinated phenol [25] from the family of Phenoxyacetic acid herbicides $[26,27]$, which may be produced by the deformation of 2,4Dichlorophenoxyacetic acid and triclosan [28]. This compound has high toxicity and resistance to degradation and the bioaccumulation potential of $2,4-\mathrm{DCP}$ is significant $[26,29]$. The biological half-life of $2,4-\mathrm{DCP}$ is between 20 and 312 days [30]. Dichlorophenols (DCPs) are considered class B2 (moderate toxicity) herbicides by the World Health Organization (WHO) [26]. The US Environmental Protection Agency (EPA) has identified DCPs as dangerous pollutants [29]. There is an increasing trend in using 2,4DCP herbicide due to its low cost, and its effectiveness in controlling a wide range of weeds [30].

Triclocarban (TCC) is a carbanilide $\left(3,4,4^{\prime}{ }^{\prime}\right.$-Trichlorocarbanilide) [31]. TCC is an antimicrobial and fatsoluble substance used in a wide range of personal care products, including soaps, toothpaste, shampoos, and detergents [24, 32-34]. Also, environmental pollution by TCC due to its widespread use, population growth, and high environmental resistance has increased its entry into wastewater, sediments, and many water sources [35, 36]. Inadequate removal of TCC in wastewater treatment plants and its high environmental resistance can lead to its accumulation in sludge and sediments, which may enter the food chain if used in agriculture [33, 37].

Animal studies show that TCC can cause dysfunction of sexual and thyroid hormones [38, 39], cause oxidative stress, and biological disorders [24]. Pesticides such as chlorophenols have many side effects on a child's development, including neurological and metabolic outcomes such as diabetes and obesity [40]. Animal studies have also shown that exposure to phenoxy herbicides can lead to lipid peroxidation [26]. 2,4-DCP may disrupt estrogen receptors [41], cell membrane phospholipid structure [42] and cause lipid peroxidation in human red blood cells [28]. TCC and 2,4DCP enter the body mainly through swallowing and skin [26]. These substances have been observed in blood and urine $[25,43]$.

There are a limited number of studies showing the relationship between EDCs (phthalates, bisphenol A) with cardiovascular risk factors in children and adolescents in Iran $[19,44-48]$. The present study aimed to measure the TCC and 2,4-DCP concentrations and their relationship with predictors of cardiovascular diseases among children and adolescents in Kerman, Iran.

\section{Materials and Methods}

2.1. Study Population. The present cross-sectional study was conducted on children and adolescents in Kerman, Iran, in 2020. Random sampling was performed on eligible people.

To calculate the sample size, taking into account the correlation coefficient $(r)$ of 0.3 , the type I error $(\alpha)$ was 0.05 , and the test power $\left(z_{1-\beta}\right)$ was $80 \%$ and using the following formulas, the sample size was 100 , which due to the increase in costs, 79 samples were measured [45].

$$
n=\left[\frac{z_{1-(\alpha / 2)}+z_{1-\beta}}{c}\right]^{2}+3 C=\frac{1}{2} \ln \frac{1+r}{1-r} .
$$

The inclusion criteria were having no history of chronic illness, participants aged 6 to 18 years, no long-term use of drugs, and living in Kerman for at least a year. A questionnaire was used to obtain demographic information and the physical activity of participants in the study $[19,44]$.

According to standard protocols, physical examinations included measurements of height, weight, waist circumference, and blood pressure. The people's height was measured using a meter in a standing position while they were wearing no shoes in a position where three points of the body (heel, back of the head, buttocks) are tangential to the wall. Waist Circumference (WC) was measured using a tape meter in the exhaled position and from the deepest area of the waist between the chest and pelvis. Weight was measured using a digital scale while the person was wearing the lightest clothes. Body Mass Index (BMI) was also calculated using the formula (dividing the weight in kilograms by the height in meters squared). Then, the BMI z score of individuals was calculated by entering age and sex using WHO AnthroPlus 
software. Blood pressure (diastolic blood pressure (DBP), Systolic blood pressure (SBP)) was measured from the right hand in a sitting position using a digital sphygmomanometer. Suitable cuff was used for children [44, 49, 50].

A total of $2 \mathrm{ml}$ of blood was taken from participants on an empty stomach (no food intake for least 8 hours before the test) to perform the following lipid profile tests: TC, TG, LDL, HDL, and fasting blood sugar (FBS) $[9,44]$. The Hitachi 704 automatic analyzer (Hitachi, Tokyo, Japan) was used to determine the serum level of these samples. Urine samples were also taken from the subjects for the creatinine test performed by the Hitachi 704 automatic analyzer $[6,19]$. A total of $6 \mathrm{ml}$ of urine sample was kept in glass containers at $-20^{\circ} \mathrm{C}$ until the day of the experiment to measure the TCC and 2,4-DCP concentration [44, 51-53].

\subsection{Measurement of TCC and 2,4-DCP Concentrations in} Urine Samples. First, the urine samples stored in the freezer at $-20^{\circ} \mathrm{C}$ have been melted at room temperature [54]. Analytes were extracted by adding about $2 \mathrm{~mL}$ of hydrochloric acid to $5 \mathrm{~mL}$ of the urine sample and incubating in a shaking incubator at $70-80^{\circ} \mathrm{C}$ for one and a half hours. Then $1 \mathrm{~mL}$ of tert-Butyl methyl ether (MTBE) solvent was added to it and placed in a vortex shaker for 5 minutes. Afterward, $100 \mu \mathrm{L}$ of Hexane was added to it in a dry vial.

The sample extracted from the previous step was transferred to a vial for the GC apparatus and $5 \mu \mathrm{L}$ of the $\mathrm{N}$-Trimethylsilyl-N-methyl trifluoroacetamide (MSTFA) derivatizing reagent and placed in the oven at $50^{\circ} \mathrm{C}$ for 60 minutes. Then $1 \mu \mathrm{L}$ of this solution was injected into the gas chromatography-mass spectrometry (GC/MS). Using different column temperature programming of GC/MS and carrier gas flow rate (helium carrier gas with a purity of 99.999 and flow rate $1 \mathrm{~mL} \mathrm{~min}^{-1}$ was used). The best peak separation was achieved. Splitless was used as the GC injection technique $[44,47,55]$.

2.3. Statistical Analysis. Data analysis was carried out using SPSS (Ver. 22) and STATA (Ver. SE 12). Kolmogorov-Smirnov and Shapiro-Wilk tests were used to examine the data distribution. An independent $t$-test was used to compare the means. Univariate and multiple linear regression analysis was used to investigate the relationship between 2,4-DCP and TCC with the studied variables. Multiple logistic regression analysis was used to compare different 2,4-DCP and TCC tertiles in predictors of cardiovascular diseases and obesity by removing potential confounders.

\section{Results}

Table 1 shows the demographic information of participants. The mean age of the study population was $11.36 \pm 3.81$ years. Most of the participants were in the age range of 6-11 years (50.6\%). The majority of children and adolescents were not exposed to secondhand smoke $(81 \%)$. Parents of most children and adolescents did not have an academic (69-76\%) and made a small income (59.5\%). Most of the children and adolescents studied had moderate to high physical activity (38\%), using cosmetics (53.2\%), and the number of baths less than twice a week (50.6\%).

The results of Table 2 show the average concentration of analytes according to the individual's weight. 2,4-DCP was observed in all samples $(n=79)$ but TCC was detected in $94.93 \%$ of the samples $(n=75)$. The mean concentration $(\mu \mathrm{g} / \mathrm{L})$ of TCC and 2,4-DCP in obese patients was $5.50 \pm 2.35$, $0.29 \pm 0.13$, respectively.

Multiple regression analysis was used to investigate the relationship between analytes concentration and age, physical activity, cosmetics consumption, and the number of baths per week among boys and girls, and results showed no significant relationship between 2,4-DCP and TCC (Table 3).

Table 4 shows the effect of predictors of cardiovascular diseases and obesity on TCC and 2,4-DCP $(\mu \mathrm{g} / \mathrm{L})$ in both crude and adjusted models (adjusted by age, physical activity, BMI, BMI z-score, WC, SBP, DBP, FBS, TC, HDL, LDL, and TG).

The adjusted model showed that the TCC concentration decreased by 0.39 units in girls with increasing age (year). A one-unit increase in BMI increased the TCC concentration to 0.64 units in all subjects. The TCC concentration increased by 0.08 units for a one-unit increase in DBP.

The results also showed that the 2,4-DCP concentration decreased by 0.02 units in boys with increasing age (year). The 2,4-DCP concentration increased 0.007 units for one-unit increasing DBP in girls. The 2,4-DCP concentration in girls was increased by 0.01 units for a one-unit increase in FBS.

Table 5 shows the relationship between 2,4-DCP, TCC $(\mu \mathrm{g} / \mathrm{L})$ with the studied variables. The studied data were divided into three parts (three tertiles) based on 2,4-DCP and TCC variables. The first tertile was considered as a reference. Data in three models (model 1: crude; model 2: adjusted by age and gender; Model 3: adjusted physical activity, age, BMI z-score, WC, BMI, SBP, DBP, FBS, TC, TG, LDL, HDL) were calculated by calculating the odds ratio (OR) with 95\% confidence interval.

In Model 2, for a one-unit increase in HDL, the odds of TCC in the third tertiles was 0.88 times that of the first tertile. For a one-unit increase in LDL, the odds of TCC in the third tertiles were 1.05 times that of the first tertile. For a one-unit increase in TG, the odds of TCC in the third tertiles was 1.02 times than the first tertile.

In Model 2, for a one-unit increase in HDL, the odds of 2,4-DCP in the third tertiles was 0.92 times than the first tertile. For a one-unit increase in TG, the odds of 2,4-DCP in the third tertiles was 1.02 times than the first tertile. For a one-unit increase in LDL, the odds of 2,4-DCP in the third tertile was 1.05 times that the first tertile. In Model 3, for a one-unit increase in LDL, the odds of 2,4-DCP in the third tertiles were 1.12 times than the first tertile.

\section{Discussion}

The present study measured the concentration of urinary analytes (TCC and 2,4-DCP) in children and adolescents and investigated their relationship with predictors of cardiovascular diseases and obesity. TCC and 2,4-DCP were 
TABLE 1: Distribution of variables demographic in the population.

\begin{tabular}{|c|c|}
\hline Variables & All $n(\%)$ \\
\hline \multicolumn{2}{|l|}{ Age groups } \\
\hline $6-11$ years & $40(50.6)$ \\
\hline $12-18$ years & $39(49.4)$ \\
\hline Mean \pm SD & $11.36 \pm 3.87$ \\
\hline \multicolumn{2}{|l|}{ Smoker family } \\
\hline Nonsmokers & $64(81.0)$ \\
\hline Smokers & $15(19.0)$ \\
\hline \multicolumn{2}{|l|}{ Father education } \\
\hline Illiterate & $11(13.9)$ \\
\hline Nonacademic & $60(75.9)$ \\
\hline Academic & $8(10.1)$ \\
\hline \multicolumn{2}{|l|}{ Mother education } \\
\hline Illiterate & $7(8.9)$ \\
\hline Nonacademic & $55(69.6)$ \\
\hline Academic & $17(21.5)$ \\
\hline \multicolumn{2}{|l|}{ Household income (US\$/month) } \\
\hline $599 \geq$ & $47(59.5)$ \\
\hline $600 \leq$ & $32(40.5)$ \\
\hline \multicolumn{2}{|l|}{ Physical activity } \\
\hline Low & $19(24.1)$ \\
\hline Moderate & $30(38.0)$ \\
\hline High & $30(38.0)$ \\
\hline \multicolumn{2}{|l|}{ Cosmetic consumption } \\
\hline Yes & $42(53.2)$ \\
\hline No & $37(46.8)$ \\
\hline \multicolumn{2}{|l|}{ The number of baths (Weeks) } \\
\hline$\leq 2$ & $40(50.6)$ \\
\hline$\geq 3$ & $39(49.4)$ \\
\hline
\end{tabular}

TABle 2: - Mean concentration of analytes according to weight status.

\begin{tabular}{|c|c|c|c|c|c|c|}
\hline \multirow{2}{*}{ Analytes concentration $(\mu \mathrm{g} / \mathrm{L})$} & \multirow{2}{*}{ No. of positives all $(n=79)$} & \multicolumn{4}{|c|}{$\mathrm{Sd} \pm$ mean } & \multirow{2}{*}{$p$-value } \\
\hline & & Total & Underweight/Normal & Overweight & Obese & \\
\hline TCC & $75(4<\mathrm{LOD})$ & $4.62 \pm 1.93$ & $3.66 \pm 0.90$ & $4.66 \pm 1.64$ & $5.50 \pm 2.35$ & 0.001 \\
\hline 2,4-DCP & 79 & $0.23 \pm 0.14$ & $0.17 \pm 0.10$ & $0.22 \pm 0.19$ & $0.29 \pm 0.13$ & 0.001 \\
\hline
\end{tabular}

TABLE 3: Association between variables and concentration of urinary analytes $(\mu \mathrm{g} / \mathrm{L}) \mathrm{s}$.

\begin{tabular}{|c|c|c|c|c|c|c|c|c|}
\hline \multirow{3}{*}{ Variable } & \multicolumn{4}{|c|}{ TCC $(\mu \mathrm{g} / \mathrm{L})$} & \multicolumn{4}{|c|}{ 2,4-DCP $(\mu \mathrm{g} / \mathrm{L})$} \\
\hline & \multicolumn{2}{|c|}{ Boys } & \multicolumn{2}{|c|}{ Girls } & \multicolumn{2}{|c|}{ Boys } & \multicolumn{2}{|c|}{ Girls } \\
\hline & $\beta$ & $p$-value & $\beta$ & $p$-value & $\beta$ & $p$-value & $\beta$ & $p$-value \\
\hline \multicolumn{9}{|c|}{ Physical activity (PA) a } \\
\hline Low & Ref & - & - & - & Ref & - & - & - \\
\hline Moderate & -0.49 & 0.55 & -0.48 & 0.54 & -0.03 & 0.53 & -0.07 & 0.31 \\
\hline High & -0.36 & 0.61 & -0.71 & 0.45 & 0.02 & 0.62 & -0.06 & 0.41 \\
\hline \multicolumn{9}{|c|}{ Cosmetic consumption ${ }^{\mathrm{b}}$} \\
\hline No & Ref & - & - & - & - & - & - & - \\
\hline Yes & 0.29 & 0.61 & 0.98 & 0.13 & - & - & - & - \\
\hline \multicolumn{9}{|c|}{ The number of baths (Weeks) } \\
\hline$\leq 2$ & Ref & - & - & - & - & - & - & - \\
\hline \multirow[t]{2}{*}{$\geq 3$} & \multirow{2}{*}{\multicolumn{2}{|c|}{$R^{2}=0.09$}} & -0.53 & 0.42 & - & - & - & - \\
\hline & & & \multicolumn{2}{|c|}{$R^{2}=0.23$} & \multicolumn{2}{|c|}{$R^{2}=0.23$} & \multicolumn{2}{|c|}{$R^{2}=0.16$} \\
\hline
\end{tabular}

a: Physical Activity: low $=$ less than 5 minutes, moderate $=5$ to 30 minutes, high $=$ more than 30 minutes b,c: 2,4 -DCP is not used in personal care products.

observed in the urine samples of most children and adolescents, which indicates that the majority of people are exposed to these analytes.
The present study showed that the 2,4-DCP concentration was higher in children (6-11 years) than adolescents (12-18 years) (Table 4$)$. Children are more exposed to 
TABLE 4: The effect of the studied variables on TCC and 2,4-DCP.

\begin{tabular}{|c|c|c|c|c|c|c|}
\hline \multirow[b]{2}{*}{ Variable } & \multicolumn{3}{|c|}{ TCC $(\mu \mathrm{g} / \mathrm{L})$} & \multicolumn{3}{|c|}{$2,4-\mathrm{DCP}(\mu \mathrm{g} / \mathrm{L})$} \\
\hline & $\begin{array}{c}\text { Boys } \\
\beta\end{array}$ & $\begin{array}{c}\text { Girls } \\
\beta\end{array}$ & $\begin{array}{c}\text { Total } \\
\beta\end{array}$ & $\begin{array}{c}\text { Boys } \\
\beta\end{array}$ & $\begin{array}{c}\text { Girls } \\
\beta\end{array}$ & $\begin{array}{c}\text { Total } \\
\beta\end{array}$ \\
\hline \multicolumn{7}{|l|}{ Age } \\
\hline Crude & -0.01 & -0.05 & -0.03 & -0.002 & -0.008 & -0.006 \\
\hline $\begin{array}{l}\text { Adjusted } \\
\text { BMI }\end{array}$ & -0.17 & $-0.39^{*}$ & $-0.25^{*}$ & $-0.02^{*}$ & 0.008 & -0.01 \\
\hline Crude & 0.10 & $0.23^{*}$ & $0.17^{*}$ & $0.01^{*}$ & 0.006 & $0.009^{*}$ \\
\hline $\begin{array}{l}\text { Adjusted } \\
\text { BMI z-score }\end{array}$ & $0.43^{*}$ & $0.82^{*}$ & $0.64^{*}$ & 0.01 & -0.006 & 0.01 \\
\hline Crude & 0.25 & $0.48^{*}$ & $0.38^{*}$ & $0.02^{*}$ & 0.01 & $0.02^{*}$ \\
\hline $\begin{array}{l}\text { Adjusted } \\
\text { WC }\end{array}$ & -0.73 & $-1.60^{*}$ & $-1.05^{*}$ & -0.03 & 0.03 & -0.02 \\
\hline Crude & -0.006 & 0.03 & 0.01 & 0.001 & 0.00 & 0.001 \\
\hline $\begin{array}{l}\text { Adjusted } \\
\text { SBP }\end{array}$ & -0.01 & -0.03 & -0.01 & 0.002 & 0.00 & 0.001 \\
\hline Crude & -0.02 & -0.02 & -0.02 & 0.001 & -0.001 & 4.6 \\
\hline $\begin{array}{l}\text { Adjusted } \\
\text { DBP }\end{array}$ & -0.05 & 0.004 & -0.02 & 0.00 & -0.004 & -0.002 \\
\hline Crude & 0.02 & -0.05 & -0.01 & 0.00 & 0.003 & 0.001 \\
\hline $\begin{array}{l}\text { Adjusted } \\
\text { FBS }\end{array}$ & $0.08^{*}$ & -0.01 & 0.02 & 0.002 & $0.007^{*}$ & 0.003 \\
\hline Crude & -0.05 & -0.02 & -0.03 & -0.005 & 0.003 & -0.001 \\
\hline $\begin{array}{l}\text { Adjusted } \\
\text { TC }\end{array}$ & -0.01 & -0.009 & -0.003 & -0.002 & $0.01^{*}$ & 0.00 \\
\hline Crude & 0.02 & 0.003 & 0.008 & -0.001 & 0.00 & -3.06 \\
\hline $\begin{array}{l}\text { Adjusted } \\
\text { HDL }\end{array}$ & 0.004 & -0.001 & 0.002 & -0.001 & 0.00 & -0.001 \\
\hline Crude & -0.05 & $-0.09^{*}$ & $-0.07^{*}$ & -0.003 & -0.002 & 0.003 \\
\hline $\begin{array}{l}\text { Adjusted } \\
\text { LDL }\end{array}$ & -0.03 & -0.02 & -0.02 & 0.001 & -0.001 & 0.00 \\
\hline Crude & $0.02^{*}$ & 0.01 & $0.01^{*}$ & $0.004^{*}$ & 0.001 & $0.001^{*}$ \\
\hline $\begin{array}{l}\text { Adjusted } \\
\text { TG }\end{array}$ & -0.003 & -0.01 & -0.01 & 0.003 & 0.002 & 0.002 \\
\hline Crude & $0.01^{*}$ & $0.02 *$ & $0.01^{*}$ & $0.001^{*}$ & 0.001 & $0.001^{*}$ \\
\hline Adjusted & 0.004 & 0.004 & 0.001 & 0.00 & 0.00 & 0.00 \\
\hline
\end{tabular}

Adjusted by body mass index (BMI), BMI z-score, waist circumference (WC), Systolic blood pressure (SBP), diastolic blood pressure (DBP), fasting blood sugar (FBS), total cholesterol (TC), High-density lipoprotein (HDL), Low-density lipoprotein (LDL), triglycerides (TG), physical activity, age * $p$-value $\leq 0.05$.

environmental pollutants than adults due to behavioral characteristics, more respiration, and eating more food than our body requirement [22]. 2,4-DCP is a herbicide widely used in many agricultural products to control weeds [26]. 2,4 -DCP is easily absorbed through the skin due to its lipophilic properties [25]. Since children have a higher skinto-body ratio than adults, they may absorb a higher dose of the environmental pollutants [56].

There have been few studies on the relationship between exposure to TCC and 2,4-DCP with predictors of cardiovascular disease and obesity. The results of the present study showed a positive relationship between increased urinary concentrations of 2,4-DCP and TCC with BMI z-score and obesity. The study by Buser et al. showed that BMI z-score, $\mathrm{WC}$, and obesity increase with increasing 2,4-DCP concentration in children and adolescents aged 6 to 19 years [40]. The study by Wei et al. also showed a linear relationship between 2,4-DCP concentration and obesity [57]. The study by Xie et al. demonstrated a positive relationship between exposure to TCC with impaired glucose tolerance (IGT) and type 2 diabetes (T2DM) in women [58].

The present study showed a significant relationship between TCC and 2,4-DCP levels with lipid profiles (TG, HDL, LDL). EDCs can disrupt the metabolism of liver fatty acids, which can affect the blood lipid concentration [59]. Phenolic compounds have been shown to stimulate oxidative changes in living cells that may lead to lipid peroxidation. Lipid peroxidation can be defined as the oxidative degradation of lipids containing any number of carboncarbon double bonds. Degradation of membrane lipids alters its integrity, fluidity, and permeability, the loss of biological membrane function and the conversion of LDL to nonestrogenic and anti-inflammatory forms. 2,4-DCP induces lipid peroxidation and significantly increases lipid peroxidation in the animal liver [28]. Studies show that exposure to TCC affects glycolipid metabolism in rat liver [43]. TCC also has the potential to inhibit soluble epoxide hydrolase, which is effective in cholesterol synthesis $[35,60]$. 
TABLE 5: association among a urinary concentration of analytes and predictors of cardiovascular risk factors.

\begin{tabular}{|c|c|c|c|c|}
\hline \multirow{2}{*}{ Variable } & \multicolumn{2}{|c|}{$\mathrm{TCC}^{\mathrm{a}}(\mu \mathrm{g} / \mathrm{L})$} & \multicolumn{2}{|c|}{$2,4-\mathrm{DCP}^{\mathrm{b}}(\mu \mathrm{g} / \mathrm{L})$} \\
\hline & Tertile $2^{\mathrm{c}}$ OR $(95 \% \mathrm{CI})$ & Tertiles $3^{\mathrm{d}}$ OR $(95 \% \mathrm{CI})$ & Tertile 2 OR $(95 \%$ CI $)$ & Tertiles 3 OR $(95 \%$ CI) \\
\hline \multicolumn{5}{|l|}{ SBP } \\
\hline Model 1 & $1.01(0.96-1.07)$ & $0.97(0.92-1.02)$ & $1.00(0.95-1.05)$ & $1.01(0.96-1.07)$ \\
\hline Model 2 & $1.01(0.96-1.07)$ & $0.97(0.92-1.03)$ & $1.00(0.95-1.05)$ & $1.02(0.97-1.08)$ \\
\hline Model 3 & $1.04(0.94-1.14)$ & $0.97(0.87-1.07)$ & $1.02(0.92-1.12)$ & $0.99(0.89-1.11)$ \\
\hline \multicolumn{5}{|l|}{$\mathrm{DBP}$} \\
\hline Model 1 & $1.01(0.95-1.07)$ & $0.98(0.92-1.04)$ & $0.99(0.93-1.06)$ & $1.02(0.96-1.08)$ \\
\hline Model 2 & $1.008(0.95-1.06)$ & $0.97(0.91-1.04)$ & $0.99(0.93-1.06)$ & $1.01(0.95-1.08)$ \\
\hline Model 3 & $0.99(0.90-1.09)$ & $1.01(0.90-1.14)$ & $0.99(0.89-1.11)$ & $1.04(0.92-1.19)$ \\
\hline \multicolumn{5}{|l|}{ HDL } \\
\hline Model 1 & $0.92(0.86-0.98)^{*}$ & $0.90(0.84-0.97)^{*}$ & $1.00(0.95-1.05)$ & $0.94(0.89-1.00)$ \\
\hline Model 2 & $0.91(0.84-0.98)^{*}$ & $0.88(0.82-0.95)^{*}$ & $1.00(0.95-1.06)$ & $0.92(0.86-0.99)^{*}$ \\
\hline Model 3 & $0.93(0.84-1.04)$ & $0.93(0.83-1.04)$ & $1.04(0.94-1.16)$ & $0.98(0.85-1.13)$ \\
\hline \multicolumn{5}{|l|}{ LDL } \\
\hline Model 1 & $1.04(1.01-1.08)^{*}$ & $1.05(1.01-1.09)^{*}$ & $1.03(1.00-1.07)^{*}$ & $1.05(1.02-1.09)^{*}$ \\
\hline Model 2 & $1.05(1.01-1.09)^{*}$ & $1.05(1.01-1.09)^{*}$ & $1.03(1.00-1.07)^{*}$ & $1.05(1.02-1.09)^{*}$ \\
\hline Model 3 & $1.01(0.95-1.06)$ & $0.99(0.93-1.05)$ & $1.03(0.97-1.09)$ & $1.12(1.03-1.22)^{*}$ \\
\hline \multicolumn{5}{|l|}{ TG } \\
\hline Model 1 & $1.01(0.99-1.02)$ & $1.02(1.005-1.03)^{*}$ & $1.00(0.99-1.02)$ & $1.02(1.00-1.04)^{*}$ \\
\hline Model 2 & $1.01(0.99-1.02)$ & $1.02(1.006-1.04)^{*}$ & $1.00(0.99-1.02)$ & $1.02(1.01-1.04)^{*}$ \\
\hline Model 3 & $0.99(0.97-1.01)$ & $1.00(0.97-1.02)$ & $1.00(0.97-1.02)$ & $1.01(0.98-1.04)$ \\
\hline \multicolumn{5}{|l|}{$\mathrm{TC}$} \\
\hline Model 1 & $1.01(0.99-1.04)$ & $1.01(0.99-1.04)$ & $1.02(0.99-1.04)$ & $1.00(0.98-1.03)$ \\
\hline Model 2 & $1.02(0.99-1.04)$ & $1.01(0.99-1.04)$ & $1.02(0.99-1.04)$ & $1.00(0.97-1.02)$ \\
\hline Model 3 & $1.01(0.98-1.05)$ & $1.01(0.98-1.05)$ & $1.01(0.97-1.04)$ & $0.96(0.92-1.01)$ \\
\hline \multicolumn{5}{|l|}{ FBS } \\
\hline Model 1 & $1.002(0.92-1.08)$ & $1.009(0.93-1.09)$ & $1.02(0.96-1.09)$ & $1.02(0.96-1.09)$ \\
\hline Model 2 & $0.98(0.91-1.07)$ & $1.01(0.92-1.09)$ & $1.03(0.96-1.11)$ & $1.03(0.97-1.11)$ \\
\hline Model 3 & $1.02(0.92-1.13)$ & $1.06(0.93-1.20)$ & $1.00(0.92-1.10)$ & $1.00(0.92-1.10)$ \\
\hline
\end{tabular}

a- The studied data were divided into three parts based on the variable TCC. b- The studied data were divided into three parts based on the variable 2,4-DCP. C, d- Tertile one is referenced Model 1: crude, Model 2: Adjusted by age and gender, Model 3: Adjusted by DBP, SBP, LDL, HDL, TG, TC, FBS, BMI z-score, WC, BMI, age, physical activity ${ }^{*} p$-value $\leq 0.05$.

The present study showed a significant relationship between TCC and 2,4-DCP concentrations with and DBP. TCC and 2,4-DCP can disrupt the endocrine system to some extent by binding to nuclear receptors, interfering with sexual and thyroid hormones [34, 61-63]. Since steroid hormones play a role in regulating blood pressure, for example, estrogen, progesterone, and testosterone receptors in blood vessels relax blood vessels and inhibit vascular smooth muscle contraction mechanisms by stimulating endothelialdependent mechanisms, it can be assumed that these chemicals may affect blood pressure [64].

In vivo experiments show that TCC has high potency in inhibiting enzyme soluble epoxide hydrolase (sEH). The sEH exerts its cardiovascular effects during processes including vasodilation, antitransmission measures on vascular smooth muscle cells, and anti-inflammatory procedures. This enzyme is also involved in cholesterol synthesis, which proves that TCC can alter the function of biological inflammation, pain, and blood pressure [35, 60, 65].

The present study showed a significant relationship between 2,4-DCP concentration and FBS. Type 2 diabetes is characterized by abnormally high blood glucose levels [66]. EDCs can interfere with insulin secretion and function [67]. By targeting alpha cells in the pancreas, EDCs disrupt molecular signals, which in turn induces glucagon release when blood glucose levels are low, consequently increasing the risk of diabetes [68]. 2,4-DCP as an EDC can affect the expression of estrogen receptors [41]. Experiments on laboratory animals show that 2,4-DCP affects $17 \beta$-estradiol levels [27]. Estradiol can be a stimulant and promoter of type 2 diabetes (estradiol is associated with changes in glucose homeostasis) [69].

Despite the results of the present study, different EDCs may have different or contradictory impacts. For example, obese people do not always have diabetes or insulin resistance, but there are people who, despite being underweight or having normal weight, suffer from serious metabolic problems such as insulin resistance and type 2 diabetes $[66,70]$.

\section{Limitation and Strengths of the Study}

The present study has several strengths such as examining the effect of 2,4-DCP and TCC on most predictors of cardiovascular disease and obesity and evaluating the effects of TCC and 2,4-DCP on the sensitive population (children and adolescents) as new research in Iran. The present study has limitations such as low sample size and being a cross-sectional study that requires longitudinal and interventional studies to investigate the effective factors. 


\section{Conclusion}

The present study showed that exposure to TCC and 2,4DCP in childhood and adolescence can be a potential risk factor for the development of cardiovascular disease and obesity indices. In the present study, higher 2,4-DCP and TCC concentrations were observed among children aged 6-11 years and there was a significant relationship between the mean concentration of analytes and weight status. Also, after the removal of possible confounders, we found a relationship between 2,4-DCP and TCC with DBP and lipid profile as well as 2,4-DCP with FBS was observed. Since childhood and adolescence, obesity can lead to health problems in adulthood. Environmental pollution control should be considered as a health priority to prevent noncommunicable diseases. This study could also warn us of stricter regulations to reduce the use of TCC and herbicides such as 2,4-DCP in consumable and agricultural products in developing countries, especially Iran.

\section{Data Availability}

The data that support the findings of this study are available upon request from the corresponding author, Majid Hashemi. The data are not publicly available due to their containing information that could compromise the privacy of research participants.

\section{Ethical Approval}

All procedures performed in the present study involving human participants were by the ethical standards of the institutional and/or national research committee.

\section{Consent}

Written informed consent was obtained from the parents.

\section{Conflicts of Interest}

All authors certify that they have no affiliations with or involvement in any organization or entity with any financial interest or nonfinancial interest in the subject matter or materials discussed in this manuscript.

\section{Acknowledgments}

The authors wish to thank the Vice Chancellor of Research of Kerman University of Medical Sciences for approving the present study. The research was approved by the Ethics Committee of Kerman University of Medical Sciences (Ethical code: IR.KMU.REC.1400.266, project code: 400000353).

\section{References}

[1] C. Friedemann, C. Heneghan, K. Mahtani, M. Thompson, R. Perera, and A. M. Ward, "Cardiovascular disease risk in healthy children and its association with body mass index: systematic review and meta-analysis," BMJ, vol. 345, p. e4759, 2012.
[2] A. C. Skinner, E. M. Perrin, L. A. Moss, and J. A. Skelton, "Cardiometabolic risks and severity of obesity in children and young adults," New England Journal of Medicine, vol. 373, no. 14, pp. 1307-1317, 2015.

[3] G. El-Kassas and F. Ziade, "Exploration of the risk factors of generalized and central obesity among adolescents in North Lebanon," Journal of environmental and public health, vol. 2017, Article ID 2879075, 13 pages, 2017.

[4] J. Legler, T. Fletcher, E. Govarts et al., "Obesity, diabetes, and associated costs of exposure to endocrine-disrupting chemicals in the European Union," Journal of Clinical Endocrinology \& Metabolism, vol. 100, no. 4, pp. 1278-1288, 2015.

[5] P. Santos, "The role of cardiovascular risk assessment in preventive medicine: a perspective from Portugal primary health-care cardiovascular risk assessment," Journal of environmental and public health, vol. 2020, Article ID 1639634, 7 pages, 2020.

[6] N. Khalil, A. Chen, and M. Lee, "Endocrine disruptive compounds and cardio-metabolic risk factors in children," Current Opinion in Pharmacology, vol. 19, pp. 120-124, 2014.

[7] N. Mustafa, H. Abd Majid, Z. Toumpakari et al., "The association of breakfast frequency and cardiovascular disease (CVD) risk factors among adolescents in Malaysia," Nutrients, vol. 11, no. 5, p. 973, 2019.

[8] H. Nasab, M. Mirzaee, K. Ebrahimpour, and M. Hashemi, "Association of urinary triclosan and methyl-triclosan levels with predictive indicators of cardiovascular disease and obesity in children and adolescents in 2020 (case study: Kerman, Iran)," Environmental Health Engineering and Management, vol. 8, no. 3, pp. 187-195, 2021.

[9] A. Klisić, N. Kavarić, and A. Ninić, "Serum cystatin C levels are associated with triglycerides/high-density lipoprotein cholesterol ratio in adolescent girls ages between 16-19 years old," European Review for Medical and Pharmacological Sciences, vol. 24, no. 20, pp. 10680-10686, 2020.

[10] B. Bjelakovic, C. Stefanutti, V. Vukovic et al., "Lipid profile and left ventricular geometry pattern in obese children," Lipids in Health and Disease, vol. 19, pp. 109-117, 2020.

[11] A. J. Muhihi, M. A. Njelekela, R. N. M. Mpembeni et al., "Elevated blood pressure among primary school children in Dar es salaam, Tanzania: prevalence and risk factors," BMC Pediatrics, vol. 18, no. 1, pp. 54-58, 2018.

[12] J. Xue, Q. Wu, S. Sakthivel, P. V. Pavithran, J. R. Vasukutty, and K. Kannan, "Urinary levels of endocrine-disrupting chemicals, including bisphenols, bisphenol A diglycidyl ethers, benzophenones, parabens, and triclosan in obese and non-obese Indian children," Environmental Research, vol. 137, pp. 120-128, 2015.

[13] M. Zarean and P. Poursafa, "The role of environmental disruptor chemicals in the development of non communicable disease," Primordial Prevention of Non Communicable Disease, Springer, Berlin, Germany, 2019.

[14] J. T. Kim and H. K. Lee, "Childhood obesity and endocrine disrupting chemicals," Annals of Pediatric Endocrinology \& Metabolism, vol. 22, no. 4, pp. 219-225, 2017.

[15] A. Arhab, N. Messerli-Bürgy, and T. H. Kakebeeke, "Childcare correlates of physical activity, sedentary behavior, and adiposity in preschool children: a cross-sectional analysis of the SPLASHY study," Journal of environmental and public health, vol. 2018, Article ID 9157194, 2018.

[16] S. Marí-Bauset, C. Donat-Vargas, A. Llópis-González, A. Marí-Sanchis, I. Peraita-Costa, and J. Llopis-Morales, "Endocrine disruptors and autism spectrum disorder in pregnancy: a review and evaluation of the quality of the 
epidemiological evidence," Children, vol. 5, no. 12, p. 157 , 2018.

[17] R. Pazos, C. Palacios, and A. Campa, "Urinary paraben concentration and its association with serum triglyceride concentration in 2013-2014 nhanes participants: a crosssectional study," Journal of Environmental and Public Health, vol. 2020, p. 8196014, 2020.

[18] H. Shaaban and W. Alhajri, "Usage patterns of cosmetic and personal care products among female population in Saudi arabia: important factors for exposure and risk assessment," Journal of environmental and public health, vol. 2020, Article ID 8434508, 8 pages, 2020.

[19] M. M. Amin, K. Ebrahimpour, S. Parastar et al., "Association of urinary concentrations of phthalate metabolites with cardiometabolic risk factors and obesity in children and adolescents," Chemosphere, vol. 211, pp. 547-556, 2018.

[20] H.-S. Kang, M.-S. Kyung, A. Ko et al., "Urinary concentrations of parabens and their association with demographic factors: a population-based cross-sectional study," Environmental Research, vol. 146, pp. 245-251, 2016.

[21] A. Chanlongbutra, G. K. Singh, and C. D. Mueller, "Adverse childhood experiences, health-related quality of life, and chronic disease risks in rural areas of the United States," Journal of Environmental and Public Health, vol. 2018, Article ID 7151297, 15 pages, 2018.

[22] C. Sun, D. P. Burgner, A. L. Ponsonby, R. Saffery, R. C. Huang, and P. J. Vuillermin, "Effects of early-life environment and epigenetics on cardiovascular disease risk in children: highlighting the role of twin studies," Pediatric Research, vol. 73, no. 2, pp. 523-530, 2013.

[23] F. Maqbool, S. Mostafalou, H. Bahadar, and M. Abdollahi, "Review of endocrine disorders associated with environmental toxicants and possible involved mechanisms," Life Sciences, vol. 145, pp. 265-273, 2016.

[24] Z.-M. Ding, M. J. Ahmad, F. Meng et al., "Triclocarban exposure affects mouse oocyte in vitro maturation through inducing mitochondrial dysfunction and oxidative stress," Environmental Pollution, vol. 262, p. 114271, 2020.

[25] J. H. Exon, G. M. Henningsen, C. A. Osborne, and L. D. Koller, "Toxicologic, pathologic, and immunotoxic effects of 2, 4-dichlorophenol in rats," Journal of Toxicology and Environmental Health, Part A Current Issues, vol. 14, no. 5-6, pp. 723-730, 1984.

[26] K. Magnoli, C. S. Carranza, M. E. Aluffi, C. E. Magnoli, and C. L. Barberis, "Herbicides based on 2, 4-D: its behavior in agricultural environments and microbial biodegradation aspects," A review. Environmental Science and Pollution Research, vol. 2020, pp. 1-12, 2020.

[27] C. Zhang, D. Li, T. Ge, J. Han, Y. Qi, and D. Huang, "2,4Dichlorophenol induces feminization of zebrafish (Danio rerio) via DNA methylation," The Science of the Total Environment, vol. 708, p. 135084, 2020.

[28] B. Bukowska, P. Wieteska, M. Kwiatkowska, P. Sicińska, and J. Michalowicz, "Evaluation of the effect of 2,4-dichlorophenol on oxidative parameters and viability of human blood mononuclear cells (in vitro)," Human \& Experimental Toxicology, vol. 35, no. 7, pp. 775-784, 2016.

[29] J. Michałowicz, A. Włuka, M. Cyrkler, A. Maćczak, P. Sicińska, and K. Mokra, "Phenol and chlorinated phenols exhibit different apoptotic potential in human red blood cells (in vitro study)," Environmental Toxicology and Pharmacology, vol. 61, pp. 95-101, 2018.

[30] F. Islam, J. Wang, M. A. Farooq et al., "Potential impact of the herbicide 2,4-dichlorophenoxyacetic acid on human and ecosystems," Environment International, vol. 111, pp. 332351, 2018.

[31] R. J. Witorsch and J. A. Thomas, "Personal care products and endocrine disruption: a critical review of the literature," Critical Reviews in Toxicology, vol. 40, no. sup3, pp. 1-30, 2010.

[32] V. Christen, P. Crettaz, A. Oberli-Schrämmli, and K. Fent, "Some flame retardants and the antimicrobials triclosan and triclocarban enhance the androgenic activity in vitro," Chemosphere, vol. 81, no. 10, pp. 1245-1252, 2010.

[33] A. J. Duleba, M. I. Ahmed, M. Sun et al., "Effects of triclocarban on intact immature male rat," Reproductive Sciences, vol. 18, no. 2, pp. 119-127, 2011.

[34] J. Chen, K. C. Ahn, N. A. Gee et al., "Triclocarban enhances testosterone action: a new type of endocrine disruptor?" Endocrinology, vol. 149, no. 3, pp. 1173-1179, 2008.

[35] N. H. Schebb, B. Inceoglu, K. C. Ahn, C. Morisseau, S. J. Gee, and B. D. Hammock, "Investigation of human exposure to triclocarban after showering and preliminary evaluation of its biological effects," Environmental Science \& Technology, vol. 45, no. 7, pp. 3109-3115, 2011.

[36] Y. Tong, B. K. Mayer, and P. J. McNamara, "Triclosan adsorption using wastewater biosolids-derived biochar," Environmental Sciences: Water Research \& Technology, vol. 2, no. 4, pp. 761-768, 2016.

[37] I. Tamura, K. Kagota, Y. Yasuda, S. Yoneda, J. Morita, and N. Nakada, "Ecotoxicity and screening level ecotoxicological risk assessment of five antimicrobial agents: triclosan, triclocarban, resorcinol, phenoxyethanol and p-thymol," Journal of Applied Toxicology, vol. 33, no. 11, pp. 1222-1229, 2013.

[38] A. Baumann, W. Lohmann, T. Rose et al., "Electrochemistrymass spectrometry unveils the formation of reactive triclocarban metabolites," Drug Metabolism and Disposition, vol. 38, no. 12, pp. 2130-2138, 2010.

[39] Y. Wang, P. Li, Y. Liu, B. Chen, J. Li, and X. Wang, "Determination of triclocarban, triclosan and methyl-triclosan in environmental water by silicon dioxide/polystyrene composite microspheres solid-phase extraction combined with HPLC-ESI-MS," Journal of Geoscience and Environment Protection, vol. 01, no. 02, pp. 13-17, 2013.

[40] M. C. Buser, H. E. Murray, and F. Scinicariello, "Association of urinary phenols with increased body weight measures and obesity in children and adolescents," The Journal of Pediatrics, vol. 165, no. 4, pp. 744-749, 2014.

[41] Y. Ma, J. Han, Y. Guo et al., "Disruption of endocrine function in in vitro H295R cell-based and in in vivo assay in zebrafish by 2,4-dichlorophenol," Aquatic Toxicology, vol. 106-107, pp. 173-181, 2012.

[42] B. Bukowska, "Effects of 2,4-D and its metabolite 2,4dichlorophenol on antioxidant enzymes and level of glutathione in human erythrocytes," Comparative Biochemistry and Physiology - Part C: Toxicology \& Pharmacology, vol. 135, no. 4, pp. 435-441, 2003.

[43] M. Dong, X. Xu, Q. Huang et al., "Dose-dependent effects of triclocarban exposure on lipid homeostasis in rats," Chemical Research in Toxicology, vol. 32, no. 11, pp. 2320-2328, 2019.

[44] M. M. Amin, K. Ebrahim, M. Hashemi et al., "Association of exposure to Bisphenol A with obesity and cardiometabolic risk factors in children and adolescents," International Journal of Environmental Health Research, vol. 29, no. 1, pp. 94-106, 2019.

[45] S. Parastar, K. Ebrahimpour, M. Hashemi et al., "Association of urinary concentrations of four chlorophenol pesticides with cardiometabolic risk factors and obesity in children and 
adolescents," Environmental Science and Pollution Research, vol. 25, no. 5, pp. 4516-4523, 2018.

[46] M. M. Amin, N. Rafiei, P. Poursafa et al., "Association of benzene exposure with insulin resistance, SOD, and MDA as markers of oxidative stress in children and adolescents," Environmental Science and Pollution Research, vol. 25, no. 34, pp. 34046-34052, 2018.

[47] M. M. Amin, S. Parastar, K. Ebrahimpour et al., "Association of urinary phthalate metabolites concentrations with body mass index and waist circumference," Environmental Science and Pollution Research, vol. 25, no. 11, pp. 11143-11151, 2018.

[48] M. M. Amin, M. Tabatabaeian, A. Chavoshani et al., "Paraben content in adjacent normal-malignant breast tissues from women with breast cancer," Biomedical and Environmental Sciences:Biomedical and Environmental Sciences, vol. 32, no. 12, pp. 893-904, 2019.

[49] R. Kelishadi, G. Ardalan, M. Qorbani et al., "Methodology and early findings of the fourth survey of childhood and adolescence surveillance and prevention of adult non-communicable disease in Iran: the CASPIAN-IV study," International Journal of Preventive Medicine, vol. 4, no. 12, pp. 1451-60, 2013.

[50] P. R. Camaj, J. H. Graziano, E. Preteni et al., "Long-term effects of environmental lead exposure on blood pressure and plasma soluble cell adhesion molecules in young adults: a follow-up study of a prospective cohort in Kosovo," Journal of environmental and public health, vol. 2018, p. 3180487, 2018.

[51] S. Lu, L. Ren, Y. Liu et al., "Urinary parabens in children from South China: implications for human exposure and health risks," Environmental Pollution, vol. 254, p. 113007, 2019.

[52] M. R. Rooney, P. L. Lutsey, P. Bhatti, and A. Prizment, "Urinary 2,5-dicholorophenol and 2,4-dichlorophenol concentrations and prevalent disease among adults in the national health and nutrition examination survey (NHANES)," Occupational and Environmental Medicine, vol. 76, no. 3, pp. 181-188, 2019.

[53] M. Hashemi, M. M. Amin, A. Chavoshani, N. Rafiei, K. Ebrahimpour, and R. Kelishadi, "Relationship of urinary phthalate metabolites with cardiometabolic risk factors and oxidative stress markers in children and adolescents," Journal of Environmental and Public Health, vol. 2021, Article ID 5514073, 12 pages, 2021.

[54] J. Yin, L. Wei, Y. Shi, J. Zhang, Q. Wu, and B. Shao, "Chinese population exposure to triclosan and triclocarban as measured via human urine and nails," Environmental Geochemistry and Health, vol. 38, no. 5, pp. 1125-1135, 2016.

[55] H. Park and K. Kim, "Concentrations of 2,4-dichlorophenol and 2,5-dichlorophenol in urine of Korean adults," International Journal of Environmental Research and Public Health, vol. 15 , no. 4 , p. 589, 2018.

[56] G. L. Ginsberg and S. J. Balk, "Consumer products as sources of chemical exposures to children," Current Opinion in Pediatrics, vol. 28, no. 2, pp. 235-242, 2016.

[57] Y. Wei, J. Zhu, and A. Nguyen, "Urinary concentrations of dichlorophenol pesticides and obesity among adult participants in the US National Health and Nutrition Examination Survey (NHANES) 2005-2008," International Journal of Hygiene and Environmental Health, vol. 217, no. 2-3, pp. 294-299, 2014.

[58] X. Xie, C. Lu, M. Wu et al., "Association between triclocarban and triclosan exposures and the risks of type 2 diabetes mellitus and impaired glucose tolerance in the National
Health and Nutrition Examination Survey (NHANES 20132014)," Environment International, vol. 136, p. 105445, 2020.

[59] W. Huang, P. Xie, and Z. Cai, "Lipid metabolism disorders contribute to hepatotoxicity of triclosan in mice," Journal of Hazardous Materials, vol. 384, p. 121310, 2020.

[60] L. A. Geer, B. F. G. Pycke, J. Waxenbaum, D. M. Sherer, O. Abulafia, and R. U. Halden, "Association of birth outcomes with fetal exposure to parabens, triclosan and triclocarban in an immigrant population in Brooklyn, New York," Journal of Hazardous Materials, vol. 323, pp. 177-183, 2017.

[61] M. Ghisari and E. C. Bonefeld-Jorgensen, "Effects of plasticizers and their mixtures on estrogen receptor and thyroid hormone functions," Toxicology Letters, vol. 189, no. 1, pp. 67-77, 2009.

[62] M. Goodman, D. Q. Naiman, and J. S. LaKind, "Systematic review of the literature on triclosan and health outcomes in humans," Critical Reviews in Toxicology, vol. 48, no. 1, pp. 1-51, 2018.

[63] H. Liu, J. Li, W. Xia et al., "Blood pressure changes during pregnancy in relation to urinary paraben, triclosan and benzophenone concentrations: a repeated measures study," Environment International, vol. 122, pp. 185-192, 2019.

[64] R. L. dos Santos, F. B. da Silva, R. F. Ribeiro, and I. Stefanon, "Sex hormones in the cardiovascular system," Hormone Molecular Biology and Clinical Investigation, vol. 18, no. 2, pp. 89-103, 2014.

[65] A. Baummann, W. Lohmann, T. Rose, K. C. Ahn, B. D. Hammock, and U. Karst, "Electrochemistry-mass spectrometry unveils the formation of reactive triclocarban (TCC) metabolites," Drug Metabolism and Disposition, vol. 38, 2010.

[66] P. Alonso-Magdalena, I. Quesada, and A. Nadal, "Endocrine disruptors in the etiology of type 2 diabetes mellitus," Nature Reviews Endocrinology, vol. 7, no. 6, pp. 346-353, 2011.

[67] D. Ruiz, M. Becerra, J. S. Jagai, K. Ard, and R. M. Sargis, "Disparities in environmental exposures to endocrine-disrupting chemicals and diabetes risk in vulnerable populations," Diabetes Care, vol. 41, no. 1, pp. 193-205, 2018.

[68] S. A. Gaston, L. S. Birnbaum, and C. L. Jackson, "Synthetic chemicals and cardiometabolic health across the life course among vulnerable populations: a review of the literature from 2018 to 2019," Current environmental health reports, vol. 7, no. 1, pp. 30-47, 2020.

[69] T. L. M. Hectors, C. Vanparys, K. Van Der Ven et al., "Environmental pollutants and type 2 diabetes: a review of mechanisms that can disrupt beta cell function," Diabetologia, vol. 54, no. 6, pp. 1273-1290, 2011.

[70] C. M. Ribeiro, B. T. S. Beserra, N. G. Silva et al., "Exposure to endocrine-disrupting chemicals and anthropometric measures of obesity: a systematic review and meta-analysis," BMJ Open, vol. 10, no. 6, p. e033509, 2020. 